\title{
UV-C IRRADIATION OF FRESHLY SQUEEZED GRAPE JUICE AND MODELING INACTIVATION KINETICS
}

\author{
SEVCAN UNLUTURK* and MEHMET R. ATILGAN ${ }^{1 *}$ \\ Department of Food Engineering, Izmir Institute of Technology, Urla, Izmir 35430 Turkey
}

\author{
${ }^{1}$ Corresponding author. \\ Department of Food Engineering, \\ Engineering Faculty, Izmir Institute of \\ Technology, Urla Izmir 35430, Turkey. \\ TEL: +90-232-7506296; \\ FAX: +90-232-7506196; \\ EMAIL: mehmetatilgan@iyte.edu.tr \\ *Both authors have equal contributions in this \\ article.
}

Received for Publication November 24, 2013 Accepted for Publication April 2, 2014

doi:10.1111/jfpe.12099

\begin{abstract}
UV inactivation kinetics of freshly squeezed turbid white grape juice (FSTGJ) treated with an annular flow UV reactor by applying UV dosages ranging from 0 to $116.7 \mathrm{~J} / \mathrm{mL}$, at three different flow rates $(0.90,1.75$ and $3.70 \mathrm{~mL} / \mathrm{s})$, were modeled by using log-linear, Weibull, Hom and modified Chick-Watson models. FSTGJ was circulated five times in the UV system, i.e., UV exposure time was 20.33 min during processing. The populations of Escherichia coli K-12, lactic acid bacteria (LAB) and foodborne yeasts were reduced by 3.759, 4.133 and $1.604 \log$ cfu/mL, respectively, after exposure to UV dosage of $116.7 \mathrm{~J} / \mathrm{mL}$ at the lowest flow rate. The inactivation kinetics of foodborne yeasts were best described by the modified Chick-Watson model, with the least root mean squared error $\left(R M S E=0.001, R^{2}=0.999\right)$. Besides, the inactivation kinetics of E. coli $\mathrm{K}-12$ and LAB were best fitted by Weibull model $\left(R^{2}=0.999\right)$. Additionally, when the UV exposure time was increased up to $32.5 \mathrm{~min}$ (i.e., eight cycles), UV-C treatment of FSTGJ resulted in $5.341 \log \mathrm{cfu} / \mathrm{mL}$ reduction in E. coli $\mathrm{K}-12$, which meets the Food and Drug Administration requirement of a $5 \log$ reduction of microorganisms in fruit juices.
\end{abstract}

\section{PRACTICAL APPLICATIONS}

Consumer demand for high-quality fruit juice with fresh-like characteristics has markedly expanded in recent years. UV-C irradiation is a nonthermal method and allows the processing of fruit juices with a minimal or no changes in flavor, essential nutrients and vitamins. Although thermal pasteurization is the most convenient way of increasing the shelf life of fruit juices, it causes a "cook taste" in grape juice. So, in this study, the application of UV-C irradiation to process grape juice was investigated. The shape of the microbial inactivation curve is sigmoidal in UV treatment. Therefore, different kinetic models (e.g., log-linear, Weibull, Hom and modified Chick-Watson) are applied to describe the inactivation kinetics of Escherichia coli K-12, lactic acid bacteria and foodborne yeasts. Kinetic parameters (e.g., $k$ and $D$ ) and models can be used for the development of UV-C irradiation process to ensure microbial safety in juice products.

\section{INTRODUCTION}

Grape juice is used in traditional and industrial production of red or white wine (Fredericks et al. 2011) or vinegar (Antonelli et al. 2004; Dávalos et al. 2005). The inhibition of low-density lipoprotein oxidation that lowers the cholesterol in human blood might be maintained by antioxidant effect of grape juice (Frankel et al. 1998). Moreover, grape juice subserves platelet aggregation due to eicosanoid synthesis (Osman et al. 1998; Keevil et al. 2000). As a nutritional source, grape juice supplies energy, carbohydrate and vitamins $\mathrm{B}$ and $\mathrm{C}$ to the human body. However, in contrast, these nutritive factors enable growth of foodborne microorganisms, such as yeasts and lactic acid bacteria (LAB) (Garde-Cerdán et al. 2007; Márselles-Fontanet et al. 2009).

Yeast, molds and bacteria, such as Lactobacillus, Leuconostoc and thermophilic Bacillus strains, are the main 
microorganisms responsible for fresh fruit juice spoilage. Although thermal pasteurization is an effective method of killing microorganisms and extending the shelf life, it causes some undesirable effects on the quality of the product. Thus, the juice processing industry has still been searching for an alternative technique to preserve the fruit juice. In addition to these limitations, alternative nonthermal processes such as pulsed electric fields, high hydraulic pressure or ionizing radiations have been proposed to preserve and extend the shelf life of grape juice (Guerrero-Beltrán et al. 2009; Márselles-Fontanet et al. 2009).

UV-C irradiation between 200 and $280 \mathrm{~nm}$ has a germicidal effect and is used as a nonthermal process in liquid food and a decontamination process on solid food surfaces (Bolton and Linden 2003). When UV light at germicidal wavelength is absorbed by the pyrimidine bases of DNA, the hydrogen bond is ruptured. Dimerization of cytosine, cytosine-thymine and uracil molecules causes photochemical damage and interruption of cell replication in the DNA and RNA microbial structure. Finally, cross linkage of nucleic acids and proteins causes cell death (Tak et al. 2011; Mendes de Souza et al. 2013). UV-C irradiation has been commercialized as a nonthermal process for fruit juice. UV-C irradiation is applied for pasteurization of milk, fruit juice and liquid egg products (Koutchma et al. 2004; Matak et al. 2005; Geveke 2008; Keyser et al. 2008; Unluturk et al. 2008, 2010; Guerrero-Beltrán et al. 2009; Char et al. 2010; Gabriel 2012). The main objectives of this study were to investigate the efficiency of UV-C irradiation as a nonthermal pasteurization process for freshly squeezed turbid white grape juice (FSTGJ) and to model inactivation kinetics of FSTGJ samples inoculated with different microorganisms (yeasts, LAB and Escherichia coli K-12).

\section{MATERIALS AND METHODS}

The inactivation efficiency of UV-C irradiation was examined on freshly squeezed grape juice. For this purpose, FSTGJ was fermented allowing to increase the population of foodborne microorganisms, i.e., mostly yeasts and LAB. Besides, FSTGJ was also inoculated with E. coli K-12 (ATCC 25253). An S-shaped annular continuous flow UV-C reactor was especially designed for the treatment of turbid liquid foods. Inoculated or fermented grape juice samples were exposed to UV-C irradiation in the UV-C reactor having $5-\mathrm{mm}$ annular gap. Three different volumetric flow rates $(0.90,1.75$ and $3.70 \mathrm{~mL} / \mathrm{s})$ at different exposure times (10, 21, $41 \mathrm{~min}$ for 5 cycles, and $68 \mathrm{~min}$ for 8 cycles) and UV-C dose ranges $(31.1,60.0$ and $116.7 \mathrm{~J} / \mathrm{mL})$ were used for UV-C irradiation process. Log-linear, Weibull, Hom and modified Chick-Watson models have been applied to describe the inactivation kinetics of these microorganisms under the studied conditions.

\section{Raw Material}

Sultana-type Turkish white grapes (seedless) were purchased from a local market (Tesco, Kipa) in İzmir, Turkey, and pressed by a fruit juice extractor (Arçelik, İstanbul) and strained twice by a cheese cloth. Four hundred milligrams of l-ascorbic acid (Merck, Darmstadt, Germany) was added per kilogram juice as an antioxidant reagent for color protection and the solution was placed in an orbital shaker (Thermo Electron, Cincinnati, $\mathrm{OH}$ ) at $100 \mathrm{rpm}$ and $4 \mathrm{C}$ for $2-3 \mathrm{~h}$. Bitartrates were removed and juice was stored in polyethylene terephthalate polymeric bottles in the freezer $(-18 \mathrm{C})$ aseptically prior to use. This juice is the "turbid white grape juice."

\section{Physical and Optical Properties of FSTGJ}

Physical and optical properties were measured before and after UV-C treatment. All measurements were repeated three times.

Density and pH. Density and pH of FSTGJ were measured by a portable density meter (Kyoto Electronics DA, Kyoto, Japan) and a bench-top pH meter (HANNA Instruments, Smithfield, RI) at room temperature (20C). Density was measured by dipping the probe of the density meter into the sample. Temperature was kept constant by water bath (Thermo Fischer Scientific Inc., Waltham, MA) during the measurement. Then, sample was sucked through the glass probe of the density meter. Density value was recorded. $\mathrm{pH}$ was measured at room temperature.

\begin{abstract}
Absorbance. Absorbance coefficient of FSTGJ samples was measured using UV-visible spectrophotometer (Carry 100, Varian Inc., Palo Alto, CA) set at a wavelength of $254 \mathrm{~nm}$. Absorbance coefficient was determined from several dilutions of samples (1:1, 1:2, 1:5, 1:10, 1:25, 1:50, 1:100, 1:200, 1:250 and 1:500) by distilled water The measurement was carried out against distilled water, which was used as "blank."
\end{abstract}

Turbidity. Turbidity was measured by turbidimeter (HACH 2100AN IS, HACH Company, Loveland, CO). Samples were filled into quartz glass containers and directly inserted into the instrument. Results were given as nephelometric turbidity unit (NTU).

Color. CIE $L^{\star}$ (lightness), $a^{\star}$ (redness) and $b^{\star}$ (yellowness) parameters were measured using Konica Minolta CR 400 Chromometer (Konica Inc., Tokyo, Japan). Samples were 
TABLE 1. PHYSICAL AND OPTICAL PROPERTIES OF FRESHLY SQUEEZED TURBID GRAPE JUICE

\begin{tabular}{lcc}
\hline Property & Before UV & After UV \\
\hline $\mathrm{pH}$ & $3.73 \pm 0.16$ & $3.91 \pm 0.22$ \\
Viscosity $(\mathrm{kg} / \mathrm{m} \cdot \mathrm{s})$ & $0.023 \pm 0.001$ & $0.023 \pm 0.002$ \\
Density $\left(\mathrm{kg} / \mathrm{m}^{3}\right)$ & $1042.7 \pm 2.3$ & $1042.9 \pm 1.8$ \\
$A_{254}\left(\mathrm{~cm}^{-1}\right)$ & $36.5 \pm 5.1$ & $34.7 \pm 2.6 *$ \\
$L^{*}$ (lightness) & $23.4 \pm 2.8$ & $23.3 \pm 3.5$ \\
$a^{*}$ (redness) & $-0.05 \pm 0.29$ & $-0.08 \pm 0.41$ \\
$b^{*}$ (yellowness) & $1.8 \pm 2.2$ & $1.5 \pm 1.6$ \\
Turbidity (NTU) & $151.55 \pm 80$ & $387.73 \pm 112^{*}$ \\
\hline
\end{tabular}

* Significant change $(P<0.05)$.

NTU, nephelometric turbidity unit.

filled into cylindrical quartz container and color parameters were directly measured from the bottom. During the measurement, white background surface was used.

Viscosity. Viscosity measurements were conducted using concentric cylinder viscometer (Brookfield DV II + Pro, Brookfield Engineering Lab. Inc., Middleborough, MA) at room temperature and constant shear rate $\left(100 \mathrm{~s}^{-1}\right)$. Physical and optical properties of FSTGJ were depicted in Table 1.

\section{Target Microorganisms and Cultivation}

Inoculation of FSTGJ by Foodborne Microorganisms. Natural microflora (foodborne microorganisms) was chosen as target microorganisms for FSTGJ (Lu et al. 2010; Fredericks et al. 2011). Frozen samples were first thawed and filtered. FSTGJ samples were naturally fermented (spoiled) by stirring at $100 \mathrm{rpm}$ and $30 \mathrm{C}$ in the orbital shaker (Thermo Electron Corp.) for 16-24 h. After fermentation, the microscopic examination revealed that the majority of foodborne microorganisms composed of mostly yeasts and LAB. Foodborne yeasts were enumerated on potato dextrose agar (PDA) by incubating at 2C for 2 days. LAB was counted on De Man Rogosa and Sharp agar (Merck) using pour-plate method after incubation at $30 \mathrm{C}$ for 2 days. Total aerobic count was carried out by spread plating of fermented FSTGJ on tryptic soy agar (TSA; Difco Corp, Sparks, MD) at $37 \mathrm{C}$ for $24 \mathrm{~h}$. FSTGJ ( $440 \mathrm{~mL}$ ) was inoculated with fermented juice $(60 \mathrm{~mL})$ in order to provide an initial inoculum level of 5-6 log cfu/mL.

Inoculation of $\boldsymbol{E}$. coli $\mathrm{K}-12$ into FSTGJ. Besides the natural microflora (yeast and LAB), E. coli K-12 (ATCC 25253), a surrogate of E. coli O157:H7 was used as a target microorganism for inoculation of FSTGJ to investigate the efficiency of UV-C inactivation on a pathogenic microorganism. E. coli K-12 (ATCC 25253) culture was adapted to pH 4 by using malic and tartaric acid following the steps described in Pala and Toklucu (2013). After acid adaptation, a single colony was transferred to $100 \mathrm{~mL}$ of tryptic soy broth (TSB) supplemented with $0.75 \%(w / v)$ glucose (Merck) and then incubated at 37C overnight. Further, $100 \mathrm{~mL}$ of enriched TSB broth was centrifuged at $750 \mathrm{rpm}$ for $5 \mathrm{~min}$ and harvested cells were directly added to $500 \mathrm{~mL}$ of grape juice to achieve a final concentration of about 6-7 log $\mathrm{cfu} / \mathrm{mL}$. To eliminate total microbial backflora, FSTGJ was pasteurized by thermal treatment before inoculation of E. coli K-12. For this aim, $100 \mathrm{~mL}$ of FSTGJ was heated in a water bath from 25 to $72 \mathrm{C}$, which is defined as the optimum pasteurization temperature for grape juice (Sanchez-Moreno et al. 2005; Timmermans et al. 2011). FSTGJ was pasteurized at 72C for 10-20 s using a water bath prior to inoculation. Temperature was controlled by a thermocouple, placed into the center of sample. Total microbial backflora was enumerated by TSA. No backflora was detected after thermal treatment. Enumeration of E. coli K-12 (ATCC 25253) was carried out on TSA using appropriate dilutions with phosphate buffered peptone solution at $3 \mathrm{C}$ for $18 \mathrm{~h}$. To determine the possible inactivation by the effect of highly acidic environment of grape juice, the acid-adapted culture prepared in TSB having $\mathrm{pH}$ adjusted to 4.0 and 3.6 was tested by inoculating into grape juice (Pala and Toklucu 2013). Acid-adapted TSB broth samples were centrifuged at 3,000 rpm for $5 \mathrm{~min}$ at $4 \mathrm{C}$. Cells were inoculated to $100 \mathrm{~mL}$ of FSTGJ with initial concentration of $10^{7-8} \mathrm{cfu} / \mathrm{mL}$. Inoculated grape juice was incubated at $37 \mathrm{C}$ for $24 \mathrm{~h}$ and enumerated after $2,4,6,7,10$ and $24 \mathrm{~h}$ on TSA.

\section{Continuous Flow UV Reactor}

The schematic diagram of completed S-shaped UV-C pasteurization system is shown in Fig. 1. The UV-C system was designed and manufactured at Food Engineering Department in Izmir Institute of Technology, Turkey. UV reactor was made from annular quartz glass tube surrounded by a cylindrical aluminum reflector (Afe Olgunlar Inc., Izmir, Turkey). It is equipped with seven UV-C lamps (UVP XX-15, UVP Inc., Upland, CA). The lamps are $15 \mathrm{~W}$ lowpressure mercury arcs, which emit primarily at $253.7 \mathrm{~nm}$. One UV-C lamp was positioned in the middle of the quartz tube, whereas the remaining six UV-C lamps were installed around the quartz tube. The gap size for annular flow was $5 \mathrm{~mm}$. A cooling jacket was used around the glass storage tank to control the temperature of the UV-C-treated liquid. A peristaltic pump (Watson Marlow Inc., Cornwall, 

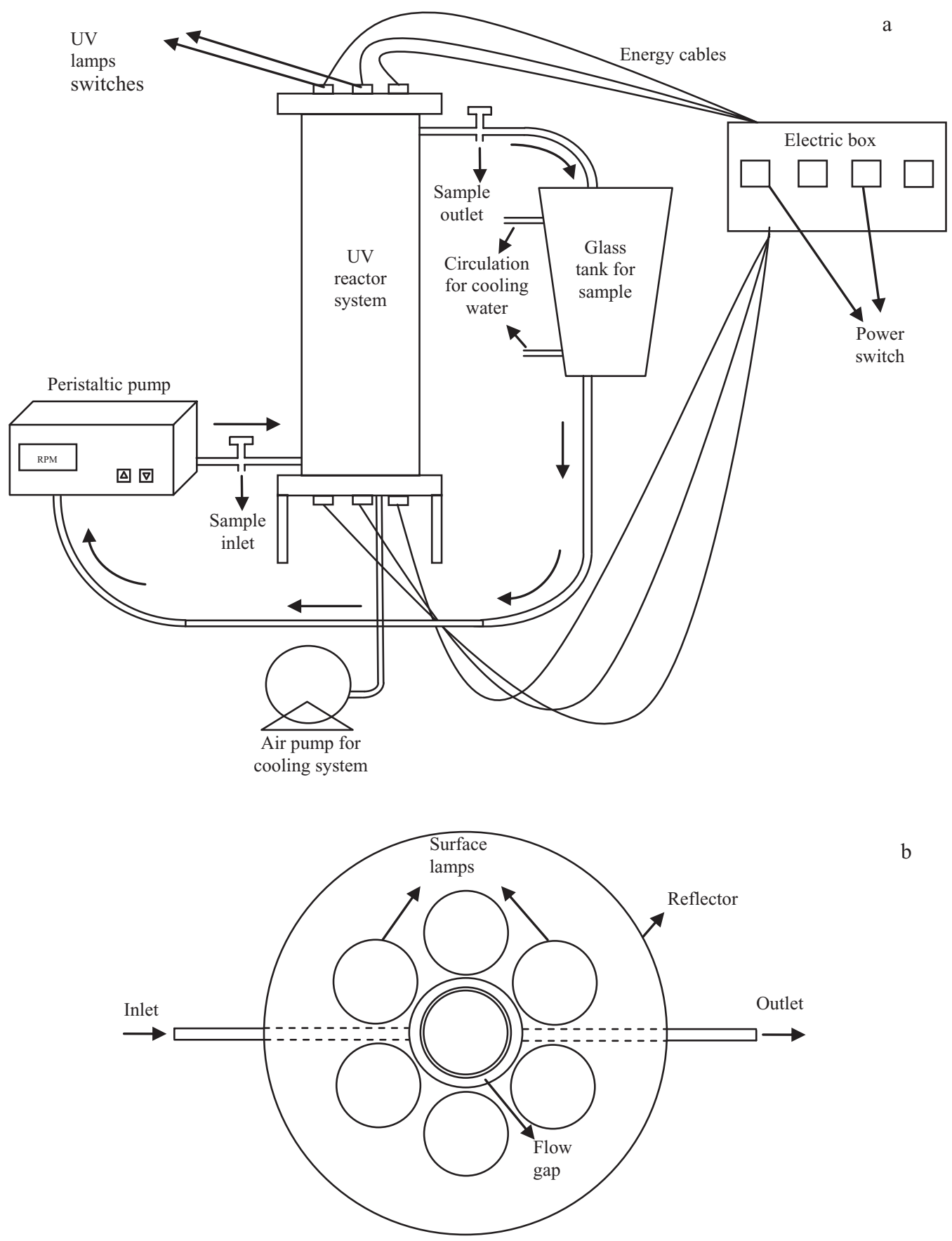

b

FIG. 1. (A) SCHEMATIC VIEW OF CONTINUOUS FLOW S-SHAPED UV SYSTEM WITH FLOW DIRECTION (B) LAMP CONFIGURATION (TOP-VIEW)

England) was utilized to pump the liquid from inlet through the outlet tube at different flow rates.

\section{UV-C Treatments}

Inoculated samples were placed in the glass tank equipped with the cooling jacket. UV-C treatments were carried out at three flow rates $(0.90,1.75$ and $3.70 \mathrm{~mL} / \mathrm{s})$ by circulating five or eight times. The residence time of UV exposure for one cycle was estimated by the ratio of residence time of flow volume of UV tube $(-220 \mathrm{~mL})$ to overall cycle time of total volume $(500 \mathrm{~mL})$ of grape juice for each flow rate, as shown in Table 2 . The velocity of fluid $(\mathrm{m} / \mathrm{s})$ was estimated from the volumetric flow rate of sample $\left(\mathrm{m}^{3} / \mathrm{s}\right)$ inlet flux 
TABLE 2. FLOW PARAMETERS OF FRESHLY SQUEEZED TURBID GRAPE JUICE

\begin{tabular}{|c|c|c|c|c|}
\hline $\begin{array}{l}\text { Velocity } \\
(\mathrm{m} / \mathrm{s})\end{array}$ & $\begin{array}{l}\text { Volumetric } \\
\text { flow rate } \\
(\mathrm{mL} / \mathrm{s})\end{array}$ & $\begin{array}{l}\text { UV exposure } \\
\text { time (s) } \\
\text { per cycle }\end{array}$ & $\operatorname{Re}$ & $\begin{array}{l}\text { UV dose } \\
(\mathrm{J} / \mathrm{mL})\end{array}$ \\
\hline 0.00164 & 0.90 & 244 & 291 & 116.7 \\
\hline 0.00315 & 1.75 & 127 & 607 & 60.0 \\
\hline 0.00677 & 3.70 & 59 & 1203 & 31.1 \\
\hline
\end{tabular}

area $\left(\mathrm{m}^{2}\right)$. The whole flow volume was collected in the glass sample tank at the end of one total cycle time during UV operation. Then, the next cycle was started. UV-C exposure time was recorded manually. Reynolds number $(R e)$ was calculated in terms of the laminar flow regime using Eq. (1) (Telis-Romero et al. 2006):

$$
R e=\frac{D_{\text {inlet }} \nu_{\text {inlet }} \rho_{\text {sample }}}{\mu_{\text {sample }}}
$$

where $R e$ is the Reynolds number, $D_{\text {inlet }}$ is the inlet diameter $(\mathrm{m}), v_{\text {inlet }}$ is the average flow velocity at the inlet $(\mathrm{m} / \mathrm{s}), \rho_{\text {sample }}$ is the sample density $\left(\mathrm{kg} / \mathrm{m}^{3}\right)$ and $\mu_{\text {sample }}$ is the apparent viscosity $(\mathrm{kg} / \mathrm{m} \cdot \mathrm{s})$. UV dose was calculated according to studies carried out by Keyser et al. (2008) and Tran and Farid (2004). It is based on the relation of lamp power and volumetric flow rate depicted in Eq. (2):

$$
\text { UV Dose }=\frac{P}{Q}
$$

where $P$ is the UV-C output (W) and $Q$ is the volumetric flow rate $(\mathrm{mL} / \mathrm{s})$. Flow parameters and applied UV doses used in experiments are given in Table 2. Sampling was performed after each cycle for microbial analysis. UV-C experiments were replicated twice for each flow rate. The survival curves of microorganisms were drawn by plotting $\log (\mathrm{N} /$ $N_{0}$ ) reductions versus time $(\mathrm{min})$.

\section{Modeling of UV-C Inactivation Kinetics}

Nonlinear UV-C inactivation curve is mainly composed of three sections, i.e., shoulder, linear and tailing regions. "Shoulder" effect is noticed when there is an initial delay of inactivation at the beginning of treatment (Marugán et al. 2008). If the disinfection rate slows down at the end of process, this part of inactivation curve is named as the "tailing" region (Van Boekel 2002; Buzrul and Alpas 2007; Bialka et al. 2008; Marugán et al. 2008). The nonlinear microbial inactivation curves are modeled using different empirical models.

Log-Linear Model. Log-linear model (Eq. 3) assumes that death of microorganisms follows the rule of first-order kinetics (Van Boekel 2002; Marugán et al. 2008):

$$
\log _{10}\left(\frac{N}{N_{0}}\right)=-k t
$$

where $N_{0}$ and $N$ are the number of untreated and treated microorganisms $(\mathrm{cfu} / \mathrm{mL})$, and $k\left(\mathrm{~min}^{-1}\right)$ is the inactivation rate constant. $D(\mathrm{~min})$ is the decimal reduction time; time required for one log reduction in number of cells and it is equal to $1 / k . D$ value is calculated from the reciprocal of the first-order rate constant commonly used to characterize the UV-C sensitivity of microorganisms.

Weibull Model. Weibull model is a simple model and is usually used to describe the concavity or convexity of nonlinear survival curves as a function of inactivation time or UV dose (Van Boekel 2002; Buzrul and Alpas 2007; Bialka et al. 2008). Weibull model is described in Eq. (4):

$$
\log _{10}\left(\frac{N}{N_{0}}\right)=-\frac{1}{2.303}\left(\frac{t}{\alpha}\right)^{\beta}
$$

where $\alpha$ is the scale parameter and $\beta$ represents the shape parameter (or concavity index). Upward concavity of the inactivation curve indicates stress adaptation of target microorganism, survived after UV-C exposure $(\beta<1)$. Downward concavity shows accumulated damaging rates of $\mathrm{UV}-\mathrm{C}$ in the cells $(\beta>1)$. The reliable time $\left(t_{R}\right)$ is the lifetime, indicating $90 \%$ reduction of the number of microbial cells (Van Boekel 2002). It is similar to $D$ value but it shows high dependency on $\beta$. $t_{R}$ for UV-C inactivation is calculated using Eq. (5) (Van Boekel 2002; Bialka et al. 2008):

$$
t_{R}=\alpha(2.303)^{\frac{1}{\beta}}
$$

Modified Chick-Watson Model. In order to describe the outward convexity or inward concavity in the inactivation curve, Chick-Watson model could be modified by introducing two parameters (Eq. 6) (Marugán et al. 2008):

$$
\log \frac{N}{N_{0}}=-k_{1}\left[1-\exp \left(-k_{2} t\right)\right]
$$

where $k_{1}$ is the dimensionless inactivation rate constant for the linear part of the curve and $k_{2}$ is the first-order UV-C decay constant $\left(\mathrm{min}^{-1}\right)$, representing the tailing effect of decelerated inactivation.

Hom Model. Hom model incorporates the parameter " $h$ ". The expression is

$$
\log \left(\frac{N}{N_{0}}\right)=-k^{\prime} t^{h}
$$

where $k^{\prime}$ is the inactivation rate constant $\left(\mathrm{min}^{-1}\right)$ and " $h$ " is the UV-C penetration rate constant. When $h=1$, model 
simplifies to log-linear equation (Eq. 3). For the case $h<1$, the equation permits the fitting of the tailing part of the inactivation curve. For $h>1$, the shoulder part is predicted (Marugán et al. 2008).

Model Comparison and Statistical Analysis. Inactivation data and model parameters were expressed as average \pm standard deviation. The parameters in the Weibull distribution, log-linear, Hom equation and modified ChickWatson equation were estimated by a computer code written with MATLAB (MATLAB 7.1, Mathworks Inc., Natic, MA). In order to determine the suitability of fitted functions, the root mean squared error (RMSE) was computed using the calculated and experimental data by Eq. (8):

$$
R M S E=\sqrt{\frac{1}{n} \sum\left[\left(\log \frac{N}{N_{0}}\right)_{\mathrm{cal}}-\left(\log \frac{N}{N_{0}}\right)_{\text {exp }}\right]^{2}}
$$

Quality parameters were expressed as average \pm standard deviation. Student's $t$-test was conducted on data for significance of parameters.

\section{RESULTS AND DISCUSSION}

\section{Inactivation of Foodborne Yeasts and LAB in FSTGJ}

The number of foodborne yeasts in FSTGJ was reduced by 1.604 (from $6.337 \mathrm{log} \mathrm{cfu} / \mathrm{mL}$ of the initial load) and $1.313 \log \mathrm{cfu} / \mathrm{mL}$ (from $5.309 \log \mathrm{cfu} / \mathrm{mL}$ of the initial load) at flow rates of $0.90 \mathrm{~mL} / \mathrm{s}(20.3 \mathrm{~min}$ of exposure time and $116.7 \mathrm{~J} / \mathrm{mL}$ of UV dose) and $1.75 \mathrm{~mL} / \mathrm{s}$ (10.6 min of exposure time and $60 \mathrm{~J} / \mathrm{mL}$ of UV dose), respectively, after circulating five times in the system. Reductions were presented in Fig. 2. Higher numbers of LAB were inactivated under the same conditions ( 4.133 and $3.966 \mathrm{log} \mathrm{cfu} / \mathrm{mL}$ from 5.522 and $5.500 \log \mathrm{cfu} / \mathrm{mL}$ of initial loads) compared to foodborne yeasts. Inefficient inactivation of yeasts can be explained with the high absorbance coefficient and turbidity of FSTGJ. UV-C light penetration might be also poor due to suspended particles found in FSTGJ causing scattering of UV-C light during treatment. Gabriel (2012) inactivated E. coli $\mathrm{O} 157: \mathrm{H} 7$ and foodborne yeasts in apple juice by UV-C and heat treatment. It was found that foodborne yeasts were more UV-C resistant than E. coli O157:H7. Char et al. (2010) studied single and combined treatment effect of ultrasound and UV-C light on E. coli in apple and pulp orange juice. As a result of suspended pulp particles and colored compounds, they claimed that UV-C disinfection was inefficient for orange juice due to poor UV-C transmission. LAB found in the background flora might be competing with yeasts to get enough UV-C light. Therefore, they
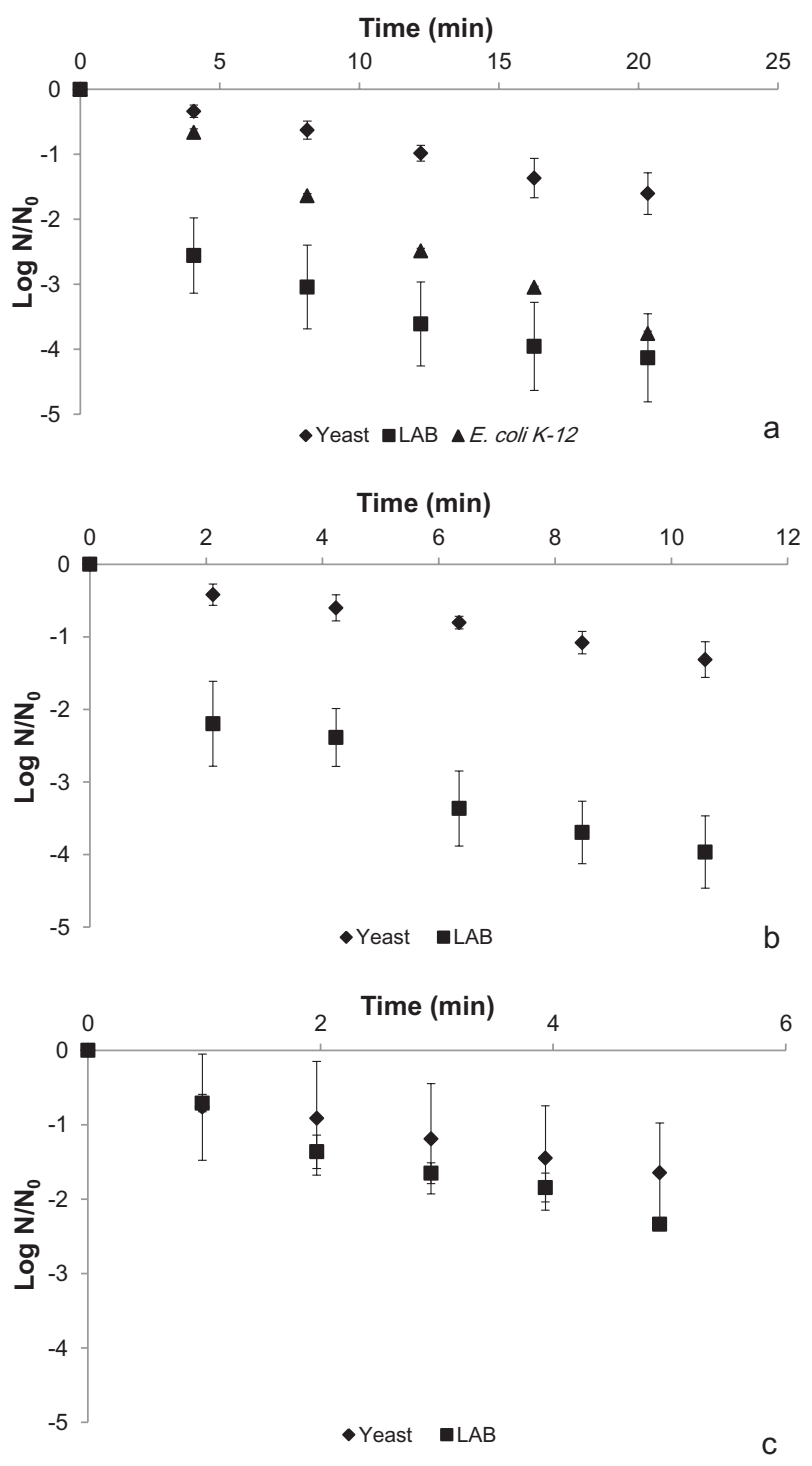

FIG. 2. UV INACTIVATION OF YEAST, LACTIC ACID BACTERIA (LAB) AND ESCHERICHIA COLI K-12 IN FRESHLY SQUEEZED TURBID GRAPE JUICE: (A) $Q=0.90 \mathrm{ML} / \mathrm{S}$; (B) $Q=1.75 \mathrm{ML} / \mathrm{S} ; \mathrm{AND}$ (C) $Q=3.70 \mathrm{ML} / \mathrm{S}$

have a higher chance to be inactivated when exposed to UV-C irradiation since LABs are much smaller than yeast cells and have different DNA material. Additionally, shadowing effect caused by aggregation of natural flora may lead to an increase in absorption coefficient of juice product which may result in reduction of UV-C light penetration. Besides, it was shown that natural foodborne flora was more resistant to UV-C irradiation than inoculated microorganisms (Linden and Darby 1998; Koutchma et al. 2004; Tran and Farid 2004; Oteiza et al. 2010). Tran and Farid (2004) studied the effect of UV-C treatment of bacteria, yeast and mold in orange juice. They explained the difference between inactivation data of bacteria and yeast in a similar manner. 


\section{Inactivation of $E$. coli $\mathrm{K}-12$ in FSTGJ}

After application of five cycles, i.e., UV-C exposure time of $20.33 \mathrm{~min}, 3.759 \log \mathrm{cfu} / \mathrm{mL}$ reductions were achieved for E. coli K-12 (ATCC 25253) from $8.689 \log \mathrm{cfu} / \mathrm{mL}$ of the initial load suspended in FSTGJ at $116.7 \mathrm{~J} / \mathrm{mL}$ of UV dose (Fig. 2a). The main reason for UV-C inactivation of E. coli $\mathrm{K}-12$ at $0.90 \mathrm{~mL} / \mathrm{s}$ was the investigation of best microbial reduction for yeast and $\mathrm{LAB}$ at lowest flow rate. When the UV-C exposure time was increased up to $32.5 \mathrm{~min}$ (i.e., eight cycles), UV-C treatment of FSTGJ resulted in $5.341 \mathrm{log}$ $\mathrm{cfu} / \mathrm{mL}$ reduction at the same initial load in E. coli $\mathrm{K}-12$, which meets the Food and Drug Administration (FDA) requirement of a $5 \mathrm{log}$ reduction of microorganisms in fruit juices. Murakami et al. (2006) found a decrease in UV-C inactivation efficiency of E-coli K-12 when suspended particles increased in fruit juices, e.g., turbid apple juice. This was due to lack of penetration of UV-C light reaching the target microorganism. The flow rate was also an important factor for the efficiency of continuous flow UV-C treatment. Koutchma et al. (2004) applied UV-C light to apple cider to inactivate E. coli K-12 using laminar and turbulent flow UV reactor systems. The authors stated that UV dose ranges between 90 and $150 \mathrm{~mJ} / \mathrm{cm}^{2}$ was necessary for a decimal reduction in turbulent $\mathrm{UV}$ reactor system at $1,250 \mathrm{~mL} / \mathrm{s}$ flow. Nonetheless, UV dose in the range of 18.8-25.1 mJ/ $\mathrm{cm}^{2}$ was required in thin film UV reactor for one decimal reduction at $56.8 \mathrm{~mL} / \mathrm{s}$. The authors determined that turbulent flow was not appropriate for highly turbid fruit juice such as apple cider. Due to different physicochemical properties of the turbid and clear apple juices, they observed that absorbance coefficient of juice products was directly affected inactivation efficiency of E. coli K-12. Similarly, Geveke (2008) applied UV-C irradiation in liquid egg white in order to inactivate E. coli K-12. Due to high absorptive property of liquid egg white, the author applied $44 \mathrm{~J} / \mathrm{mL}$ of UV dose to reduce the number of E. coli K-12 by $4.3 \mathrm{cfu} /$ mL. Le et al. (2010) inactivated $>5$ log unit of E. coli with a dose of $540 \mathrm{~J} / \mathrm{mL}$ in pasteurized and freshly squeezed apple juice and $180 \mathrm{~J} / \mathrm{mL}$ in beer. It was observed that yeasts were more resistant to UV-C irradiation than E. coli K-12 suspended in FSTGJ. Palgan et al. (2011) determined lower inactivation rate for Pichia fermentans yeasts than that of E. coli using single or combined nonthermal treatment for fresh apple and cranberry juices. Overall, the results of this study showed that the UV system was affectively designed to inactivate E. coli K-12 in FSTGJ.

\section{Changes in Physical and Optical Properties of FSTGJ}

Physical and optical properties including absorbance coefficient, $\mathrm{pH}$, color and turbidity of grape juice samples were measured before and after UV treatment and summarized in Table 1. $\mathrm{pH}$, density, viscosity and color parameters $\left(L^{*}\right.$, $a^{\star}$ and $\left.b^{\star}\right)$ of FSTGJ did not change significantly by the effect of UV treatment $(P<0.05)$. On the contrary, change in the absorbance coefficient level of PCGJ was significant. Absorbance coefficient of untreated PCGJ was $36.5 \pm 5.1 \mathrm{~cm}^{-1}$ and reduced to $34.7 \pm 2.6 \mathrm{~cm}^{-1}$ after UV treatment. Decrease in absorbance coefficient might be due to degradation of vitamin C (ascorbic acid) by UV irradiation (Koutchma et al. 2009). Tran and Farid (2004) found $17 \%$ loss of vitamin C in orange juice at $100 \mathrm{~mJ} / \mathrm{cm}^{2}$ of UV exposure. It was observed that turbidity level of the treated samples increased significantly from $151.55 \pm 80$ NTU to $387.73 \pm 112$ NTU after UV treatment. Similarly, Tandon et al. (2003) determined significant changes in the turbidity of UV-irradiated $\left(14 \mathrm{~mJ} / \mathrm{cm}^{2}\right.$ at $\left.254 \mathrm{~nm}\right)$ apple cider during storage. It was expected that the untreated and UV-treated samples showed an increase in turbidity during storage time due to an increase in the number of foodborne yeast and bacteria producing visible sediment and cloud in juice products (Tandon et al. 2003; Chia et al. 2012).

\section{Modeling Inactivation Kinetics}

The microbial inactivation curves obtained from the application of UV-C irradiation to FSTGJ samples exhibited both linear and a slight tailing behavior (Fig. 2). The shoulder effect was negligible. The tailing might be due to the suspended solid particles in the medium and/or cell aggregation caused by improper mixing. This behavior results in nonhomogeneous irradiation and nonlinear inactivation kinetics (Unluturk et al. 2008, 2010). Thus, modeling of inactivation kinetics was carried out by both log-linear and nonlinear models, i.e., Weibull, Hom and modified Chick-Watson.

Log-Linear Model. In order to correlate low $k$ values of log-linear model, inactivation data were scattered. $k$ values of $\mathrm{LAB}\left(0.3782 \mathrm{~min}^{-1}\right)$ were higher than those of yeast $\left(0.1423 \mathrm{~min}^{-1}\right)$ and E. coli $\mathrm{K}-12\left(0.3327 \mathrm{~min}^{-1}\right)$ in FSTGJ at the lowest flow rate (Table 3 ). The reason for the difference between the yeast and $\mathrm{LAB}$ was clarified in the previous section. Decimal reduction time $(D)$ was also estimated by using $k$ values obtained from the first-order inactivation kinetics. Foodborne yeast in FSTGJ showed the highest $D$ value $(10.03 \mathrm{~min})$ at the highest flow rate. Increase of flow rate during UV-C exposure resulted high $D$ values for each microbial population. These results might be maintained due to the inefficient contact of UV-C light to cell populations by low residence time. On the contrary, turbid structure of FSTGJ might be affected by mixing at high flow rate, resulting in an increase in absorption coefficient of juice product (Koutchma et al. 2004; Tran and Farid 2004). 
TABLE 3. LOG-LINEAR MODEL PARAMETERS FOR SPOILAGE YEASTS, LACTIC ACID BACTERIA (LAB) AND ESCHERICHIA COLI K-12 EXPOSED TO UV IRRADIATION

\begin{tabular}{|c|c|c|c|c|c|c|}
\hline \multirow[b]{2}{*}{ Microorganism } & \multicolumn{3}{|l|}{$k\left(\min ^{-1}\right)$} & \multicolumn{3}{|l|}{$D(\min )$} \\
\hline & $0.90 \mathrm{~mL} / \mathrm{s}$ & $1.75 \mathrm{~mL} / \mathrm{s}$ & $3.70 \mathrm{~mL} / \mathrm{s}$ & $0.90 \mathrm{~mL} / \mathrm{s}$ & $1.75 \mathrm{~mL} / \mathrm{s}$ & $3.70 \mathrm{~mL} / \mathrm{s}$ \\
\hline Yeast & 0.1423 & 0.1087 & 0.0987 & 7.027 & 9.191 & 10.032 \\
\hline LAB & 0.3782 & 0.3069 & 0.1928 & 2.644 & 3.258 & 5.186 \\
\hline E. coli K-12 & 0.3327 & - & - & 3.005 & - & - \\
\hline
\end{tabular}

The resistance of inactivated microorganism was determined by the comparison of the kinetic constant $\left(k^{\prime}\right)$ in Hom model. The parameter $h$ in the Hom model was calculated less than 1 for all the flow conditions. Results were represented in Table 5. UV-C light resistivity of yeast population in FSTGJ was found to be highest $\left(0.089 \pm 0.016 \mathrm{~min}^{-1}\right)$. Moreover, LAB was less resistant $\left(0.357 \pm 0.165 \mathrm{~min}^{-1}\right)$ than yeast and E.coli $\mathrm{K}-12$ $\left(0.200 \pm 0.021 \mathrm{~min}^{-1}\right)$ in the same sample. These results were supported by Gabriel (2012). In this study, E. coli O157:H7 bacteria and foodborne yeast strains were inactivated in clear pasteurized apple juice by UV-C light. Although E. coli $\mathrm{O} 157: \mathrm{H} 7$ required $2.5 \mathrm{~min}$ of exposure time for $1 \log$ cfu inactivation, 8.0 min was necessary for yeast at the same UV intensity. It was claimed that high

TABLE 4. MODIFIED CHICK-WATSON MODEL PARAMETERS FOR SPOILAGE YEASTS, LACTIC ACID BACTERIA (LAB) AND ESCHERICHIA COLI K-12 EXPOSED TO UV IRRADIATION

\begin{tabular}{|c|c|c|c|c|c|c|}
\hline \multirow[b]{2}{*}{ Microorganism } & \multicolumn{3}{|l|}{$k_{1}$} & \multicolumn{3}{|l|}{$k_{2}\left(\min ^{-1}\right)$} \\
\hline & $0.90 \mathrm{~mL} / \mathrm{s}$ & $1.75 \mathrm{~mL} / \mathrm{s}$ & $3.70 \mathrm{~mL} / \mathrm{s}$ & $0.90 \mathrm{~mL} / \mathrm{s}$ & $1.75 \mathrm{~mL} / \mathrm{s}$ & $3.70 \mathrm{~mL} / \mathrm{s}$ \\
\hline Yeast & $0.984 \pm 0.515$ & $0.843 \pm 0.362$ & $1.192 \pm 0.635$ & $0.899 \pm 0.524$ & $1.748 \pm 1.046$ & $3.293 \pm 1.139$ \\
\hline $\mathrm{LAB}$ & $3.460 \pm 0.782$ & $3.122 \pm 0.829$ & $1.622 \pm 0.562$ & $1.081 \pm 0.699$ & $2.045 \pm 1.314$ & $3.369 \pm 1.103$ \\
\hline E. coli K-12 & $2.323 \pm 1.139$ & - & - & $0.990 \pm 0.573$ & - & - \\
\hline
\end{tabular}

TABLE 5. HOM MODEL PARAMETERS FOR SPOILAGE YEASTS, LACTIC ACID BACTERIA (LAB) AND ESCHERICHIA COLI K-12 EXPOSED TO UV IRRADIATION

\begin{tabular}{|c|c|c|c|c|c|c|}
\hline \multirow[b]{2}{*}{ Microorganism } & \multicolumn{3}{|l|}{$k^{\prime}\left(\min ^{-1}\right)$} & \multicolumn{3}{|l|}{$h$} \\
\hline & $0.90 \mathrm{~mL} / \mathrm{s}$ & $1.75 \mathrm{~mL} / \mathrm{s}$ & $3.70 \mathrm{~mL} / \mathrm{s}$ & $0.90 \mathrm{~mL} / \mathrm{s}$ & $1.75 \mathrm{~mL} / \mathrm{s}$ & $3.70 \mathrm{~mL} / \mathrm{s}$ \\
\hline Yeast & $0.089 \pm 0.016$ & $0.147 \pm 0.041$ & $0.468 \pm 0.334$ & $0.960 \pm 0.038$ & $0.986 \pm 0.012$ & $0.894 \pm 0.314$ \\
\hline LAB & $0.357 \pm 0.165$ & $0.526 \pm 0.149$ & $0.582 \pm 0.122$ & $0.988 \pm 0.010$ & $0.990 \pm 0.011$ & $0.997 \pm 0.002$ \\
\hline E. coli K-12 & $0.200 \pm 0.021$ & - & - & $0.979 \pm 0.021$ & - & - \\
\hline
\end{tabular}

TABLE 6. WEIBULL MODEL PARAMETERS FOR SPOILAGE YEASTS, LACTIC ACID BACTERIA (LAB) AND ESCHERICHIA COLI K-12 EXPOSED TO UV IRRADIATION

\begin{tabular}{|c|c|c|c|c|c|c|c|c|c|}
\hline \multirow[b]{2}{*}{ Microorganism } & \multicolumn{3}{|l|}{$\alpha_{\text {ave }}(\min )$} & \multicolumn{3}{|l|}{$\beta_{\text {ave }}$} & \multicolumn{3}{|l|}{$t_{\text {Rave }}(\min )$} \\
\hline & $0.90 \mathrm{~mL} / \mathrm{s}$ & $1.75 \mathrm{~mL} / \mathrm{s}$ & $3.70 \mathrm{~mL} / \mathrm{s}$ & $0.90 \mathrm{~mL} / \mathrm{s}$ & $1.75 \mathrm{~mL} / \mathrm{s}$ & $3.70 \mathrm{~mL} / \mathrm{s}$ & $0.90 \mathrm{~mL} / \mathrm{s}$ & $1.75 \mathrm{~mL} / \mathrm{s}$ & $3.70 \mathrm{~mL} / \mathrm{s}$ \\
\hline Yeast & $1.080 \pm 0.141$ & $1.110 \pm 0.321$ & $1.158 \pm 0.374$ & $0.368 \pm 0.084$ & $0.382 \pm 0.089$ & $1.168 \pm 0.649$ & $12.792 \pm 8.637$ & $11.746 \pm 7.944$ & $4.074 \pm 3.421$ \\
\hline LAB & $1.020 \pm 0.018$ & $1.011 \pm 0.005$ & $0.937 \pm 0.150$ & $0.918 \pm 0.203$ & $1.153 \pm 0.298$ & $1.243 \pm 0.257$ & $2.657 \pm 0.457$ & $2.171 \pm 0.293$ & $1.882 \pm 0.368$ \\
\hline E. coli K-12 & $1.024 \pm 0.028$ & - & - & $0.693 \pm 0.036$ & - & - & $3.429 \pm 0.207$ & - & - \\
\hline
\end{tabular}



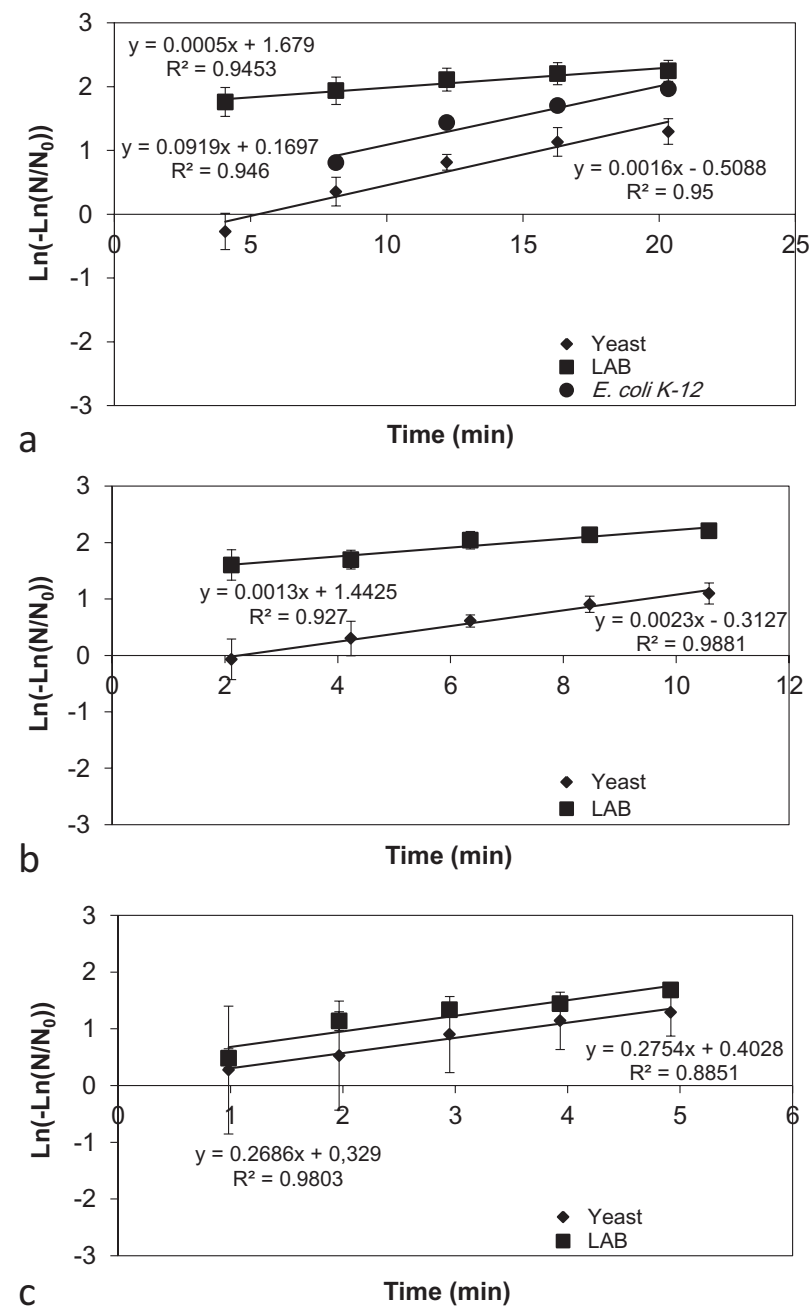

FIG. 3. THE REASONABLE PLOTS LN(-LN[N/No]) VERSUS LN(T) OF THE WEIBULL MODEL FOR DIFFERENT VOLUMETRIC FLOW RATES:

(A) $0.90 \mathrm{ML} / \mathrm{S}$; (B) $1.75 \mathrm{ML} / \mathrm{S}$; AND (C) $3.70 \mathrm{ML} / \mathrm{S}$

amount of UV-C light was absorbed by yeast, reducing UV-C treatment efficiency (Gabriel 2012).

The results of Weibull model were listed in Table 6. Applicability of Weibull model to experimental data was tested by reasonable plots of the double logarithms $\ln \left(-\ln \left[N / N_{0}\right]\right)$ versus $\ln (t)$ (Unluturk et al. 2010) depicted in Fig. 3. For minimum flow rate $(0.90 \mathrm{~mL} / \mathrm{s}), \beta$ values were seen as below 1 . This result indicated that the remaining cells are less probable to be terminated since resistance increase occurs to UV-C light at higher exposure times (Peleg 1999; Van Boekel 2002; Buzrul et al. 2005). However, in contrast, shape parameter was greater than 1 at high flow rates for each strain. This was due to the high susceptibility of microorganisms to UV-C treatment (Van Boekel 2002; Raffellini et al. 2011). Moreover, the scale parameter $\alpha$ is known as the measure of the resistance of organism to treatment. $\alpha$ was estimated to be higher for yeast than LAB for the three flow rates. Results were matched with $\log _{10}$ reduction values. It was observed that lower $\log _{10}$ reduction $(1.643 \mathrm{log} \mathrm{cfu} /$ $\mathrm{mL}$ ) was noticed for yeast than $\mathrm{LAB}$ at flow rates of $0.90,1.75$ and $3.70 \mathrm{~mL} / \mathrm{s}$. Unluturk et al. (2010) found that the scale parameter of E. coli K-12 was higher than for Listeria innocua. They also defined lower reduction for E. coli $\mathrm{K}-12$, depending on the $\alpha$ result. Reliable time $\left(t_{R}\right)$ values were compared to withdraw a definite conclusion (Table 6). $t_{R}$ value of yeast was much higher than that of $\mathrm{LAB}$ and E. coli K-12. Inactivation data of E. coli K-12 and $\mathrm{LAB}$ were fitted best. These findings were in agreement with Ferrario et al. (2013). They inactivated E. coli from apple, melon, orange and strawberry juices. Fittings of Weibull model on inactivation data of $E$. coli were better. Large standard deviation of $t_{R}$ might be explained with the highly turbid structure of FSTGJ causing a competitive environment for yeast population during UV-C exposure. The dependency of $\alpha$ and $\beta$ on exposure time was statistically significant when tested at the $95 \%$ significance level $(P<0.05)$. It was also seen that standard deviations for some $\alpha$ and $\beta$ values were quite large to prevent a linear relationship. Nonetheless, it was found that some data, used to determine Hom model parameters, were not used for the estimation of Weibull model parameters due to incompatibility of these data for two models. Other than $\alpha$ and $\beta, t_{R}$ was checked, while applying the Weibull model. Since the standard deviations of some of the inactivation data are quite large, these outlier data were not included in the calculations while testing the performance of the Weibull model. Therefore, Hom model parameter $(h)$ and shape parameter of Weibull model $(\beta)$ might not be comparable and there are some variations in the goodness-of-fit values (Table 7). The increase in standard deviation levels was due to the experimental problems such as high UV-C light absorptivity and inhomogeneity of freshly squeezed samples, fluctuation in UV-C light during inactivation and shadowing effect of suspended particles. The models were compared based on RMSE and $R^{2}$ and were shown in Table 7. Modified Chick-Watson model parameters resulted in a very good fit of the experimental data for each microbial populations with the correlation coefficient $\left(R^{2}\right)$ higher than 0.999. Besides, Chick-Watson model parameters were more reliable compared to other models, based on lower RMSE values.

\section{CONCLUSION}

In this study, the efficiency of UV-C radiation on microbial inactivation of E. coli K-12 and foodborne microorganisms, i.e., $\mathrm{LAB}$ and yeasts in freshly squeezed turbid grape juice inoculated with different types of microorganisms, was determined by using S-shaped UV reactor at different flow 
TABLE 7. GOODNESS-OF-FIT PARAMETERS FOR MODELS

\begin{tabular}{|c|c|c|c|c|}
\hline Microorganism & Model & $\begin{array}{l}\text { Volumetric flow } \\
\text { rate }(\mathrm{mL} / \mathrm{s})\end{array}$ & RMSE & $R^{2}$ \\
\hline \multirow[t]{12}{*}{ Yeast } & \multirow[t]{3}{*}{ Linear } & 0.90 & 1.447 & 0.997 \\
\hline & & 1.75 & 0.374 & 0.986 \\
\hline & & 3.70 & 0.015 & 0.995 \\
\hline & \multirow[t]{3}{*}{ Weibull } & 0.90 & 0.0003 & 0.999 \\
\hline & & 1.75 & 0.0003 & 0.998 \\
\hline & & 3.70 & 0.081 & 0.946 \\
\hline & \multirow[t]{3}{*}{ Chick-Watson } & 0.90 & 0.0003 & 0.999 \\
\hline & & 1.75 & 0.0003 & 0.999 \\
\hline & & 3.70 & 0.0004 & 0.999 \\
\hline & \multirow[t]{3}{*}{ Hom } & 0.90 & 0.027 & 0.993 \\
\hline & & 1.75 & 0.001 & 0.999 \\
\hline & & 3.70 & 0.002 & 0.998 \\
\hline \multirow[t]{12}{*}{ LAB } & \multirow[t]{3}{*}{ Linear } & 0.90 & 3.661 & 0.922 \\
\hline & & 1.75 & 1.023 & 0.974 \\
\hline & & 3.70 & 0.132 & 0.979 \\
\hline & \multirow[t]{3}{*}{ Weibull } & 0.90 & 0.001 & 0.999 \\
\hline & & 1.75 & 0.002 & 0.998 \\
\hline & & 3.70 & 0.006 & 0.999 \\
\hline & \multirow[t]{3}{*}{ Chick-Watson } & 0.90 & 0.002 & 0.999 \\
\hline & & 1.75 & 0.0003 & 0.999 \\
\hline & & 3.70 & 0.1 & 0.997 \\
\hline & \multirow[t]{3}{*}{ Hom } & 0.90 & 0.001 & 0.998 \\
\hline & & 1.75 & 0.001 & 0.998 \\
\hline & & 3.70 & 0.006 & 0.999 \\
\hline \multirow[t]{4}{*}{ E. coli K-12 } & Linear & 0.90 & 1.551 & 0.995 \\
\hline & \multicolumn{2}{|l|}{ Weibull } & 0.0004 & 0.999 \\
\hline & \multicolumn{2}{|l|}{ Chick-Watson } & 0.011 & 0.999 \\
\hline & \multicolumn{2}{|l|}{ Hom } & 0.001 & 0.999 \\
\hline
\end{tabular}

RMSE, root mean squared error. rates. The best inactivation rate for microorganisms suspended in FSTGJ was observed at the lowest flow rate $(0.90 \mathrm{~mL} / \mathrm{s})$. The populations of E. coli K-12, LAB and foodborne yeasts were reduced by 3.759, 4.133 and $1.604 \log \mathrm{cfu} / \mathrm{mL}$, respectively, after exposure to UV dosage of $116.7 \mathrm{~J} / \mathrm{mL}$ at the lowest flow rate. Five flow cycles (20.33 min of UV-C exposure) were found inadequate to achieve $5 \log$ reductions in E. coli K-12. Therefore, the number of cycle was increased to eight, i.e., 32.5-min UV-C exposure time. In this case, UV-C treatment of FSTGJ resulted in $5.341 \log \mathrm{cfu} / \mathrm{mL}$ reductions in E. coli $\mathrm{K}-12$, which meets the FDA requirement of a $5 \mathrm{log}$ reduction of microorganisms in fruit juices. Foodborne yeasts were found to be the most resistant microorganisms to UV-C irradiation under studied conditions. $D$ values for foodborne yeasts $(7.027 \mathrm{~min})$ were higher than that of LAB (2.644 min) and E. coli K-12 (3.005 min). Modified ChickWatson model (two parameters) provided a very good fit of the inactivation data of yeasts. On the contrary, Weibull model exhibited better correlation for inactivation kinetics of E. coli K-12 and LAB $\left(R^{2}=0.999\right)$.

\section{ACKNOWLEDGMENT}

This study was supported by the Department of Food Engineering, Izmir Institute of Technology, Izmir, Turkey (2010IYTE09).

\section{REFERENCES}

ANTONELLI, A., CHINNICI, F. and MASINO, F. 2004.

Heat-induced chemical modification of grape must as related to its concentration during the production of traditional balsamic vinegar: A preliminary approach. Food Chem. 88 , 63-68.

BIALKA, K.L., DEMIRCI, A. and PURI, V.M. 2008. Modeling the inactivation of Escherichia coli O157:H7 and Salmonella enterica on raspberries and strawberries resulting from exposure to ozone or pulsed UV-light. J. Food Eng. 85, 444-449.

BOLTON, J.R. and LINDEN, K.G. 2003. Standardization of methods for fluence (UV dose) determination in bench-scale UV experiments. J. Environ. Eng. 129, 209-215. 
BUZRUL, S. and ALPAS, H. 2007. Modeling inactivation kinetics of food borne pathogens at a constant temperature. LWT - Food Sci. Technol. 40, 632-637.

BUZRUL, S., ALPAS, S. and BOZOGLU, F. 2005. Use of Weibull frequency distribution model to describe the inactivation of Alicyclobacillus acidoterrestris by high pressure at different temperatures. Food Res. Int. 38, 151-157.

CHAR, C.D., MITILINAKI, E., GUERRERO, S.N. and ALMAZORA, S.M. 2010. Use of high-intensity ultrasound and UV-C light to inactivate some microorganisms in fruit juices. Food Bioprocess Technol. 3, 797-803.

CHIA, S.L., ROSNAH, S., NORANIZAN, M.A. and WAN RAMLI, W.D. 2012. The effect of storage on the quality attributes of ultraviolet-irradiated and thermally pasteurised pineapple juices. Int. Food Res. J. 19, 1001-1010.

DÁVALOS, A., BARTOLOMÉ, B. and GÓMEZ-CORDOVÉS, C. 2005. Antioxidant properties of commercial grape juices and vinegars. Food Chem. 93, 325-330.

FERRARIO, M., ALZAMORA, S.M. and GUERRERO, S. 2013. Inactivation kinetics of some microorganisms in apple, melon, orange and strawberry juices by high intensity light pulses. J. Food Eng. 118, 302-311.

FRANKEL, E.N., BOSANEK, C.A., MEYER, A.S., SILLIMAN, K. and KIRK, L.L. 1998. Commercial grape juices inhibit the in vitro oxidation of human low-density lipoproteins. J. Agric. Food Chem. 46, 834-838.

FREDERICKS, I.N., DU TOIT, M. and KRUGEL, M. 2011. Efficacy of ultraviolet radiation as an alternative technology to inactivate microorganisms in grape juices and wines. Food Microbiol. 28, 510-517.

GABRIEL, A.A. 2012. Inactivation of Escherichia coli O157:H7 and spoilage yeasts in germicidal UV$\mathrm{C}$-irradiated and heat-treated clear apple juice. Food Control 25, 425-432.

GARDE-CERDÁN, T., ARIAS-GIL, M., MÁRSELLESFONTANET, À.R., ANCÍN-AZPILICUETA, C. and MARTÍN-BELLOSO, O. 2007. Effects of thermal and non-thermal processing treatments on fatty acids and free amino acids of grape juice. Food Control 18, 473-479.

GEVEKE, D.J. 2008. UV inactivation of E. coli in liquid egg white. Food Bioprocess Technol. 1, 201-206.

GUERRERO-BELTRÁN, J.Á., WELTI-CHANES, J. and BARBOSA-CÁNOVAS, G.V. 2009. Ultraviolet-C light processing of grape, cranberry and grapefruit juices to inactivate Saccharomyces cerevisiae. J. Food Process Eng. 32, 916-932.

KEEVIL, J.G., OSMAN, H.E., REED, J.D. and FOLTS, J.D. 2000. Grape juice, but not orange juice or grapefruit juice, inhibits human platelet aggregation. J. Nutr. 130, 53-56.

KEYSER, M., MULLER, I., CILLIERS, F.P., NEL, W. and GOUWS, P.A. 2008. UV radiation as a non-thermal treatment for the inactivation microorganisms in fruit juice. Innov. Food Sci. Emerg. Technol. 9, 348-354.

KOUTCHMA, T.N., KELLER, B., PARISI, B. and CHIRTEL, S. 2004. Ultraviolet disinfection of juice products in laminar and turbulent flow reactors. Innov. Food Sci. Emerg. Technol. 5, 179-189.

KOUTCHMA, T.N., FORNEY, L.J. and MORARU, C.I. 2009.

Ultraviolet Light in Food Technology: Principles and

Applications, 1st Ed., pp. 13-17, CRC Press, Taylor \& Francis Group, New York.

LE, G., LI, C.L., LIU, P., CUI, H.B., YAO, Y.J. and ZHANG, Q.A. 2010. UV inactivation of microorganisms in beer by a novel thin-film apparatus. Food Control 21, 1312-1317.

LINDEN, K. and DARBY, L. 1998. Ultraviolet disinfection of marginal effluents: Determining UV absorbance and subsequent estimation of UV intensity. Water Environ. Res. $70,214-223$.

LU, G., LI, C., LIU, P., CUI, H., XIA, Y. and WANG, J. 2010. Inactivation of microorganisms in apple juice using an ultraviolet silica-fiber optical device. J. Photochem. Photobiol. B. 100, 167-172.

MÁRSELLES-FONTANET, À.R., PUIG, A., OLMOS, P., MÍNGUEZ-SANZ, S. and MARTÍN-BELLOSO, O. 2009. Optimising the inactivation of grape juice spoilage organisms by pulse electric fields. Int. J. Food Microbiol. 130, 159-165.

MARUGÁN, J., GRIEKEN, R., SORDO, C. and CRUZ, C. 2008. Kinetics of the photocatalytic disinfection of Escherichia coli suspensions. Appl. Catal. B: Environ. 82, 27-36.

MATAK, K.E., CHUREY, J.J., WOROBO, R.W., SUMNERR, S.S., HOYINGH, E., HACKEY, C.R. and PIERSON, M.D. 2005. Efficacy of UV light for the reduction of Listeria monocytogenes in goat's milk. J. Food Prot. 68, 2212-2216.

MENDES DE SOUZA, P., BRIVIBA, K., MULLER, A., FERNÁNDES, A. and STAHL, M. 2013. Cyto-genotoxic and oxidative effects of a continuous UV-C treatment of liquid egg products. Food Chem. 138, 1682-1688.

MURAKAMI, E.G., JACKSON, L., MADSEN, K. and SCHICKEDANS, B. 2006. Factors affecting the ultraviolet inactivation of Escherichia coli $\mathrm{K}-12$ in apple juice and a model system. J. Food Process Eng. 29, 53-71.

OSMAN, H.E., MAALEJ, N., SHANMUGANAYAGAM, D. and FOLTS, J.D. 1998. Grape juice but not orange or grapefruit juice significantly inhibits in vivo platelet activity and thrombosis in stenosed canine coronary arteries. J. Nutr. 128(12), 2307-2312.

OTEIZA, J.M., GIANNUZZI, L. and ZARITSKY, N. 2010. Ultraviolet treatment of orange juice to inactivate E. coli O157:H7 as affected by native microflora. Food Bioprocess Technol. 3, 603-614.

PALA, C.U. and TOKLUCU, A.K. 2013. Effects of UV-C light processing on some quality characteristics of grape juices. Food Bioprocess Technol. 6, 719-725.

PALGAN, I., CAMINITI, I.M., MUÑOZ, A., NOCI, F., WHYTE, P., MORGAN, D.J., CRONIN, D.A. and LYNG, J.G. 2011. Combined effect of selected non-thermal technologies on Escherichia coli and Pichia fermentans inactivation in an apple and cranberry juice blend and on product shelf life. Int. J. Food Microbiol. 151, 1-6. 
PELEG, M. 1999. On calculating sterility in thermal and non-thermal preservation methods. Food Res. Int. 32, 271-278.

RAFFELLINI, S., SCHENCK, M., GUERRERO, S. and ALZAMORA, S.M. 2011. Kinetics of Escherichia coli inactivation employing hydrogen peroxide at varying temperatures, $\mathrm{pH}$ and concentrations. Food Control 22, 920-932.

SANCHEZ-MORENO, C., PLAZA, L., ELEZ-MARTINEZ, P., ANCOZ, B.D., MARTÍN-BELLOSO, O. and CANO, M.P. 2005. Impact of high pressure and pulsed electric fields on bioactive compounds and antioxidant activity of orange juice in comparison with traditional thermal processing. J. Agric. Food Chem. 53, 4403-4409.

TAK, Y.K., KIM, W.Y., HAN, E., KIM, M.J., KIM, J.A., LIM, C.Y. and SONG, J.M. 2011. Determination of UV-induced DNA damages to suppress protein expression using reporter gene assay-based single cell cotransfection imaging cytometry. Toxicol. Lett. 204, 25-31.

TANDON, K., WOROBO, R.W., CHUREY, J.J. and PADILLA-ZAKOUR, O.I. 2003. Storage quality of pasteurized and UV treated apple cider. J. Food Process. Preserv. 27, 21-35.
TELIS-ROMERO, J., THOMAS, C.E.P., BERNARDI, M., TELIS, V.R.N. and GABAS, A.L. 2006. Rheological properties and fluid dynamics of egg yolk. J. Food Eng. 74, 191-197.

TIMMERMANS, R.A.H., MASTWIJK, H.C., KNOL, J.J., QUATAERT, M.C.J., VERYOORT, L., VAN DER PLANCKEN, I., HENDRICKX, M.E. and MATSER, A. 2011. Comparing equivalent thermal, high pressure and pulsed electric field processes for mild pasteurization of orange juice. Part I: Impact on overall quality attributes. Innov. Food Sci. Emerg. Technol. 12, 235-243.

TRAN, M.T. and FARID, M. 2004. Ultraviolet treatment of orange juice. Innov. Food Sci. Emerg. Technol. 5, 495-502.

UNLUTURK, S., ATILGAN, M., BAYSAL, A.H. and TARI, C. 2008. Use of UV-C radiation as a non-thermal process for liquid egg products (LEP). J. Food Eng. 85, 561-568.

UNLUTURK, S., ATILGAN, M.R., BAYSAL, A.H. and UNLUTURK, M.S. 2010. Modeling inactivation kinetics of liquid egg white exposed to UV-C irradiation. Int. J. Food Microbiol. 142, 341-347.

VAN BOEKEL, M.A.J.S. 2002. On the use of the Weibull model to describe thermal inactivation of microbial vegetative cells. Int. J. Food Microbiol. 74, 139-159. 